\title{
Research on the Current Situation of Rural Cultural Practice: A Case Study of Villages and Towns in Nanyang City, Henan Province
}

\author{
LIU Huiling \\ Nanyang Institute of Technology, China \\ Received: June 6, 2021 \\ Accepted: July 25, 2021 \\ Published: November 30, 2021
}

To cite this article: LIU Huiling. (2021). Research on the Current Situation of Rural Cultural Practice: A Case Study of Villages and Towns in Nanyang City, Henan Province. Asia-Pacific Journal of Humanities and Social Sciences, 01:3, 077-082, DOI: 10.53789/j.1653-0465.2021.0103.009

To link to this article: https://doi.org/10.53789/ j.1653-0465.2021.0103.009

Abstract: Rural revitalization has been carried out in an all-round way across the country, but in the vigorous development, people feel it very difficult. At the same time, the government points out that cultural construction is the soul of rural revitalization. This paper thus studies the current rural cultural practice, hoping to offer some ideas and measures. In this paper, literature review, participation in expert reports, participation in rural planning projects and rural research are the research methods. It suggests that the construction of rural culture should stand at the height of planning villages and townships, take the cultural development of the whole area as a whole, and construct the idea of the interactive development of industry, agriculture and culture. In the construction of philosophy and sociology, daily etiquette activities must be constructed and forged as habits. Cultural activities should be a necessity of life, just like a religion, because they can help stimulate the people's cultural awareness and inherit the cultural traditions. Government should take the rural community management as a tool to strengthen the party-masses co-governance.

Keywords: cultural construction; rural revitalization; rural culture; cultural practice

Notes on the contributor: LIU Huiling holds a master's degree. Her academic interest lies in Environmental Design and Urban and Rural Planning. She works at the Nanyang Institute of Technology.

\section{新時代鄉村文化實踐現狀研究 以河南省南陽市鄉鎮為例}

\author{
劉惠玲 \\ 南陽理工學院
}

摘 要: 鄉村振興已在全國全面展開, 但在大力發展生產和創業的同時也倍感艱難。同時黨也指 
出文化建設是鄉村振興的魂, 本文以此為契機研究鄉村文化實践的現狀, 希望為文化建設找到一 些想法和措施。本文以查閲文獻資料、參加專家報告會、參與鄉村規劃專案與鄉村調研為研究手 段。最终建議: 鄉村文化建設應站在村、鄉、鎮、縣規劃的高度, 統籌看待整個片區鄉鎮的文化發 展, 構建產業文化互動發展和產業抱團發展的思想; 在哲學與社會學建設方面建議將日常禮儀活 動和傳統習俗變為習慣。通過開展週期性和程式化的文化活動, 讓文化活動成為生活的必須, 讓 文化禮儀成為一種信仰, 希望借此可以激發全民的文化自覺, 繼承和發揚優良傳統文化; 政府部門 能運用鄉村未來社區的管理概念來加強黨群共治。

關鍵詞: 文化建設; 鄉村振興; 鄉村文化; 文化實践

\section{一、鄉村文化的定義與解釋}

鄉村文化應該是包括物質文化和非物質文化兩部分組成。物質文化方面比如:村莊的選址、格局、建築 風貌、街巷、吉祥物以及自然景觀等。非物質文化包括傳統手工藝、飲食文化、傳統禮儀、傳統節日、祭祀、民 俗、傳說故事、詩歌等。如紅白喜事、廟會祭祀、地方戲曲、傳統藝術、傳說諺語、民間禁忌等,這些紮根於鄉 村土地的文化類型隨著歷史的變遷和地域差異而變化, 展示出多種多樣的具有農家韻味的鄉村意境。鄉村 文化既有抽象無形的一面,比如村落社區中的集體訴求、交往原則、處世態度、行為習慣等; 也表現為有形的 物質層面, 如民風民俗、典章制度及特定器物等。它是農民生產與生活的過程中, 逐步形塑發展起來的一種 思想觀念、心理意識和行為方式, 以及種種作為物質存在的文化產品。而村落的自然生態、倫理本位的社會 模式、士紳階層的協調模式構成中國傳統鄉村文化的基礎。1

本文的鄉村文化實踐活動研究主要是針對非物質文化展開。

\section{二、國內研究現狀分析}

研究較深人的有北京師範大學王靜 (2010 年) 發表的碩士論文 “傳統節日民俗文化在文化軟實力提升 中的作用” 具體的表述了傳統節日文化的内涵、種類及提升文化軟實力的措施。措施包括: 1. 傳承和創新傳 統節日文化; 2.加強道德教育; 3.將傳統節日文化資源融人到新產品開發中形成節日產業鏈。党文中他對道 德教育和傳統節日文化產業開發的措施列舉了許多條例,鋪展得較深人。

江陰職業技術學院王濤(2019 年) 撰寫的“淺談舞龍舞獅運動文化的傳承與價值”, 提到傳承舞獅舞龍 習俗對弘揚傳統文化有積極的作用。点北京體育大學呂韶鈞教授(2008 年) 發表的論文“民間舞獅習俗與中 國傳統文化探微”重點探源了舞獅文化的形成、發展與中國宗教文化、地域文化以及民俗文化的關係，它對 提高民族凝聚力, 維護祖國和諧統一有堅實的文化根基作用。 ${ }^{(4)}$ 山西師範大學張紅霞 (2018 年)碩士論文 “村 落社會、民俗事象與文化展演——隴中郭山村的社火研究” 以甘肅通渭縣郭山村的社火展演為個案,從“社 火作為民間小戲”、“社火作為民俗事象”、“社火作為文化展演”三個理論層面出發,通過節日情境、儀式過 程、内容構成、文化功能、現代新變與傳承危機等展開, 較為深人地探討了隴中社火的文化內涵、地域特色及 存在現狀,並為社火的當下傳承與保護提供了理論參照依據。5

以上研究更多是站在哲學與社會學的角度來分析傳統文化的傳承與發展的意義,並提出了一些措施。 


\section{三、關於鄉村生活與文化活動的描述}

\section{(一) 古代鄉村生活}

通過歷代對田園生活的詩句可以一椝古代的鄉村生活:

晉 陶淵明《歸田園居》種豆南山下, 草盛豆苗稀。晨興理荒穢, 帶月荷鋤歸。

唐 李白《下終南山過斛斯山人宿置酒》暮從碧山下, 山月隨人歸。卻顧所來徑, 蒼蒼橫翠微。

宋 翁卷《鄉村四月》綠遍山原白滿川, 子規聲裏雨如煙。鄉村四月閒人少, 才了蛀桑又插田。從這些詩 句可以看出古代的鄉村生活真是山清水秀、炊煙嫋嫋、魚米豐盛、悠然自得,非常的殹意。

\section{（二）改革開放初期鄉村生活}

改革開放初期,在湖北筆者的記憶中的農村就是人們在一起嗑瓜子、聊天、打牌; 或者是聚在村口、道場 打穀子、曬穀, 有石磨、石碾子; 或者是插积、開拖拉機、拉黃牛、推獨輪車, 那時人們相互幫助, 互相借工具, 一起勞動。還有在水塘裏洗衣服、洗菜、刷馬桶, 小孩們摸魚摸蝦。平時, 人們放牛、放羊, 上隊裏去修路、修 堤,或作木匠、瓦匠、策匠等。婦女們在街巷裏的拉鞋底、繡枕頭、打毛衣。小孩們一起玩著過家家或躲迷 藏。大型傳統節日有扭秧歌、舞龍、舞獅子、踩高蹺、劃旱船等,還有古裝扮相遊街, 有小姐、公子、媒婆、小丑 等。過年拜年最熱鬧了,大年初一家家戶戶桌子上擺上茶水、香煙、瓜子、糖果等著村上的人來拜年。村裏 婚喪嫁娶也是熱鬧非凡。偶爾晚上還跑上十幾裏地跟著鄉親們去聽戲或去看電影。

\section{四、當前南陽市鄉村文化建設方面存在的問題}

\section{(一) 鄉村生活現狀}

鄉村環境舊的村落大部分破損嚴重,基本無人居住, 人煙稀少。新建的村落有些是新舊混雜,有些雖然 建有完好的新農村,可是也是無人居住。村裏歷史傳統文化建築, 或是閒置任其破敗或是成了家禽的飬殖 場。大部分農田、莊稼地也無人耕種,幾乎荒無。文化站和文化廣場欠失維護,也已經破敗。村裏溝河雜草 叢生, 污水橫流。塑膠垃圾四處散落,有電線亂拉、小廣告滿牆的現象。

人們的生活方式也發生了轉變, 村裏基本都是留守兒童和老人, 常住人口占少數。村裏人員流動較單 一, 孩子都上來學校, 年輕的都看著手機、刷著抖音, 老年人三三兩兩聚在一起打牌或聊天。除了婚坒嫁娶, 其他民俗活動舉辦越來越少, 有些乾脆就流失了。

隨著社會經濟的發展城市建設的加快,進城務工人員的有增無減, 資訊的大量汇濫, 鄉村文化在歷史浪 潮中逐漸褪去原有的色彩, 呈現出了新的樣貌。許多的民間文藝和非物質遺產也逐漸遠去。逢年過節走親 訪友和宗族活動減少、婚喪嫁娶也簡化、市場化。文化站的公共文化服務不是注重實效, 只做面子工程, 應 付檢查。文化活動的題材也是魚目混珠,缺乏文藝性、知識含量和積極向上的正能量。

\section{(二) 分析原因}

1. 重視程度不夠 人們只顧著解決生活、生產上的困難, 如村村通公路、最低生活保障、廁改、危房改造等 問題,把主要精力放在了追求經濟增長上,而有意或無意地忽視了基層文化的建設。

2. 文化傳承欠缺 重缺乏民族文化的自信與自覺。傳統的禮教活動地沒有被好好繼承下來,因為快捷的 生活節奏, 加上老一輩文化人的過世, 文化傳統逐漸被人們遺忘, 許多的儀式禮儀都被簡化。崇洋媚外思想 
Asia-Pacific Journal of Humanities and Social Sciences

的影響和改革開放,曾一度貶低傳統禮教,使之更加惡化。

3. 管理不完善 村傳統的家族化族群居住形式發生了改變, 人員遷徙流走和遷人的現象太普遍, 傳統家 族和族群結構發生了改變。在村部管理方面, 族長話語權的流失加劇了家族禮儀活動的流失。新的村部幹 部有些自身文化修養、眼界和追求就不高, 缺乏追求高文化的責任和對傳統文化的熱情。不能盡職盡責, 淪 為應付, 存在“檢查一股風”。

4. 人才欠缺 統文䒧表演人才出現斷層, 青黄不接, 表演創作人員多數都是 60 歲以上的, 傳人難䍃, 人們 對傳統曲藝的欣賞與愛好也被流行歌曲和電視取代。部分曲藝面臨滅絕, 需要傳承。村部小學、中學和文 化站缺乏文化活動的帶頭人。上級的傳統文化宣講活動普及率和頻率也不高, 經常是一股風, 沒有長久性。

\section{五、新時代鄉村文化發展的現狀與機遇}

\section{(一) 國外經驗借鑒}

黨對鄉村建設的指引從最初的“新農村” 建設到 “美麗鄉村” 建設, 到現在的“鄉村振興”。我們不僅要 產業振興同時兼顧文化振興,兩個一起抓,相互帶動。國外鄉村振興的做法:

1. 日本政府提出了“造鄉運動”, 目的就是為了保護農村地區的非物質文化遺產和重新帶給鄉村以活 力, 在“造鄉運動” 中, 各地紛紛推出地、產、人、景、文化相結合的活動, 將本地文化融入到鄉村中的各個方 面,把單一的第一產業轉變為鄉村整體的多元文化產業,推廣“一村一品”。

2. 上世紀 70 年代,韓國的科技水準已經具有一定的實力,而由於政治動亂,朝鮮戰爭、國民經濟波動等 原因,使韓國國民的生活倫理水準——勤勉、城市、節約、自助、協同等受到嚴重的挫敗。城鄉加大差距, 農 業瀕臨破產, 於是政府通過一種具有感召力的活動——以勤勉、自助、協同為基本精神, 要求農民振奮起來, 勤勉、自助與合作, 官民一體建設家園。將原先潛在的國人倫理水準引發出來, 就釋放出了無窮的能量, 這 種具有感召力的活動, 就是後來眾所周知的韓國“新農村運動”, 它是以教育、培養、激發國民的進取、向上精 神, 依靠自身的力量創造一個民族團結、人民富裕、環境優美的新農村。中心內容就是提高國民的生活倫理 水準保持其與國民科技水準一直,通過人力資源的開發來建設新農村。

日本把單一的鄉村第一產業轉變為整體多元的文化產業, 推廣“一村一品”。韓國通過教育、培養、激發 國民的進取、向上精神從而產生生產力。這些都是很值得國人借鑒和學習的。

\section{（二）目前南陽鄉村文化建設的成果}

從鄉村的文化建設方面來看,近幾年來,鄉村文化事業雖取得了一定的可喜發展：

1. 文化基礎設施建設比較完善:具備初級的農家書屋、綜合文化站、文化廣場、體育健身場、籃球場等。

2. 文化工作取得了一定的成績,群眾自娛自樂文化活動開展的有聲有色,廣場舞、腰鼓隊、健身操、棋牌 室等。文化站組織的文藝活動也有一定的發展, 每年都有大型的活動。有戲曲下鄉的戲劇演出、影視下鄉 的電影活動。市婦聯邀請名家和講師定期也舉辦的公益課堂和道德講堂。

3. 南陽各鄉鎮還建有紅色主題廣場,宣講社會主義核心價值觀, 名人、勞模宣傳欄, 弘揚正氣, 及時傳播 黨的新政策。湧現了一批助人為樂、孝老愛親、敬業奉獻好人好事。

\section{六、新時代鄉村文化實踐活動策略}

\section{（一）新時代鄉村文化發展方向與目標}

弘揚主旋律和社會正氣、培育文明鄉風、淳樸民風、保護傳統文化村、延續名俗名風。深人挖掘中華優 
秀傳統文化蓝含的思想觀念、人文精神、道德規範, 結合時代要求, 推進中華優秀傳統文化的創造性轉化和 創新性發展。有力推動全鎮道德文明建設。培育和弘揚社會主義核心價值觀。農村文化建設的好壞, 關係 到國家發展大局。加強農村的文化建設, 改善農村文化面貌, 讓群眾更好地享受社會主義建設的成果, 實現 文化奔小康。

\section{（二）新時代鄉村文化實踐活動具體策略}

1. 民俗文化的產業化發展

(1) 產業文化互動發展戰略

根據一村一品的思想, 週期性開展民俗文化活動, 將其市場化操作, 大力進行市場開發,豐富民俗文化 内涵,促進民族文化與當地旅遊的結合。將中國傳統生活方式與現代生活方式相結合,結合新技術、新媒 體, 傳承傳統手工藝, 挖掘文化符號, 繼承傳統文化活動, 展示多元文化活動, 宣傳鄉風鄉俗, 演繹民間故事。 打造民俗旅遊專案, 大力發展非物質文化遺產的表演, 圍繞民俗文化表演製作新媒體, 民俗文化也可以結合 直播、VR 進行網路宣傳。開發當地的康養特色, 帶動相關旅遊服務產業的發展。在發展一二三產業融合中 也就豐富了當地村民的生活, 也就是產業帶動文化、文化激發產業, 產業是體, 文化是魂, 文化一一產業一 文化這種良性的迴圈互動可以極大的提高人們的物質和精神財富, 實現人人都有事可做, 人人都有角色可 演, 盤活農村的人力和技術資源,使他們為鄉村振興服務,真正實現民富村強的夢想。南京大學研究城鄉規 劃的羅震東教授在做專題報告時介紹了貴州石阶縣樓上村發展民俗旅遊的成功案例。通過充分挖掘樓上 村的村史和當地的山體、水系、動物等, 向外地遊客展示當地的植物、建築等歷史風貌的由來, 演繹當地的生 活習俗和民俗活動, 吸引了較多遊客, 成為網紅。

(2)村、鄉、鎮產業鏈抱團發展

對於有特色的鄉村產業應該通盤考虑, 全局統籌, 一起帶動式發展, 形成產業鏈。將產業鏈劃分為多個 層級級別, 由村部帶動鄉、鎮, 或是鎮帶動村部, 抱團發展, 即: 居民點文化站 (行政村、中心村級)——鄉級 (鄉級文化站)——鎮級 (鎮級文化中心) 抱團發展。

2. 開展每日程式化的家庭禮儀活動和週期性的習俗、民俗活動

根據韓國新農村的經驗, 發展農村先從思想上武裝自己, “將原先潛在的良好的國人倫理水準引發出 來, 就會釋放出了無窮的能量”。

(1) 開展每日程式化的家庭禮儀活動

發揚“朱子治家格言” 的古訓: 黎明即起,灑掃庭除, 要內外整潔, 既昏便息, 關鎖門戶, 必親自檢點。一 䉼一飯, 當思來處不易; 半絲半縷, 恒念物力維艱等等, 進行每日的家庭活動: 内務清潔, 頌讀, 禮拜, 思過等 活動, 將其程式化、儀式化。就是在固定的時間、地點, 按照固定的程式進行每日的家庭清潔、禮拜和日常 生活。

(2) 開展週期性的傳統節日、習俗、民俗文化活動

將中國重大的傳統節日: 春節、元宵節、清明節、端午節、重陽節、中秋節、臘八節等, 以及各地的習俗和 活動有效地組織起來, 讓文化活動成為生活的必須, 成為習慣, 讓文化禮儀成為一種信仰, 激發全民的文化 自覺,並繼承和發揚優良文化傳統。

\section{(3) 開展週期性的禮儀講堂教育活動}

根據豐富的中華傳統禮儀思想“修身、齊家、治國、平天下”, “忠孝節義”四德思想,還有“仁義禮智信” 五常思想,政府負責進行週期性的禮儀講堂宣講,對廣大村名及群眾進行宣傳教育。

通過典型的好人好事、孝悌忠信、鄰里和睦、教子有方等事蹟, 教育大眾, 希望能達到父母慈愛、子女孝 敬、夫婦和睦、兄弟友愛、姊妹互讓、妯娌互諒、兄弟互協。通過反面教材以抵抗那些不良之風, 如: 好逸惡 勞、損人利已、貪公營私、坑蒙拐騙、貪污受賄、偷盜淫逸、殺人越貨、崇洋媚外、走私販黃等。9 
(4) 建立科學的公共文化服務體系

在通過認真思考後, 回望農村公共文化服務體系建設的歷程, 公共文化服務要收到實效, 至少要做好兩 個層面的工作:一、是建立良好的績效評估體系;二、是加強公共服務體系的管理。

1) 績效評估體系

建立正確的績效評估問卷: (1)以村民的滿意度調研為主體, 文化活動一切為老百姓著想,一切為人民服 務, 老百姓安居樂業為目標。(2)村民的參與度為二級評價指標。(3)文化活動的社會影響力大小, 通過學 生的升學率、成功率、收人提升度、網路流量等評價。對工作成績突出、成效顯著的單位和個人給予表彰獎 勵,對工作推進不力、懶政怠政、不能按要求完成目標任務的單位和個人實施問責。

2 ) 加強管理

公共文化服務體系主體應該由政府、文化事業單位、私人社團、企業四個方面組成,並有各自的職能定 位。以政府為主導建立專項基金資助私人社團的自發活動, 資助公益性的文化並適當提供參與者一定的獎 勵和報酬。這種自下而上和自上而下的互動式活動方能激發群眾的參與度, 共同推動鄉村的文化服務體系 的建設。

發揮村民主體作用。發揮好基層黨組織核心作用和黨員帶頭作用, 健全村民自治機制, 充分運用民主 決策制度, 保障村民權益。鼓勵村民參與到文化建設和文化活動的決議中來。結合村莊實際建立文化活動 基金,按工按勞付給參與文化建設的村民一定的報酬。

(5)引進人才或聘請專家助力發展

強化技術和人才支撐。建立農村文化展演、演講省級專家庫。吸引編導、影視、文藝、演員和其他專業 技術人員下鄉進村服務, 業務指導。積極組織開展農村的文化活動和村部文化站工作人員的技術培訓, 鼓 勵高等院校、文藝編導、企業開展農村文化活動策劃和編導的關鍵內容與環節。

(6) 運用鄉村未來社區的管理概念實現黨群共治

未來社區是涵蓋創業、銷售、文化教育、建設、服務、管理為一體的綜合生活生產場所。宣導鄰里互容、 健康生活、全民創業、低碳環保，通過構建鄰里公共空間、開放空間為居民提供鄰里交流、交往、交融、交心的 人文氛圍, 構建 “遠親不如近鄰” 未來鄰里場景。憑藉鄰里公約、鄰里文化、鄰里精神標識的打造, 形成鄰里 人文內核,強化鄰里在情感上的聯結,形成鄰里精神共同體。

統籌優質網路教育資源, 開放“普惠共用”名師名校教育資源, 鼓勵支教活動。

搭建“鄰里圈” 創業舞臺、“未來創客”, 提升創業服務, 鼓勵志願者幫扶, 實現創業服務無憂。只有村民 都有事業可幹、收人提高、人們安居樂業,才能真正實現村民自我服務、黨群“三位一體”的未來社區管理。

\section{注釋}

1 趙旭東, 孫笑非: 《中國鄉村文化的再生産——基於一種文化轉型觀念的再思考》, 《南京農業大學學報(社會科學 版) 》2017 年第 1 期。

(2) 王静: 《傅統節日民俗文化在文化軟實力提升中的作用》,《北京師範大學》2010 年版, 頁 8-32。

(3) 王澍:《淺談舞龍舞獅運動文化的傳承與價值》,《廣東稳業》2019 年第 5 期。

(4) 吕韶制:《民間舞獅習俗與中國傳統文化探微》,《北京體育大學學報》2008 年第 10 期。

(5) 張紅霞:《村落社會、民俗事象與文化展演——隴中郭山村的社火研究》,《山西師範大學》2018 年版, 頁 1-70。

(6) 黄四清: 《蕽村文化發展現狀、存在的問題、對策及建議》, 《蕽家科技(下旬刊) 》2 015 年第 10 期。

(7) 華彦玲、馀文學:《韓國“新村運動”對建設我國新農村的啟示》, 《㖖灣農業探索》2007 年第 1 期。

(8)以石阶樓上古寨為例, 復旦大學專家縱論文脈與鄉村振興路垩 http://travel. gog. cn/system/2020/10/26/ 017754972.shtml

(9) 韓延明:《孔孟仁愛思想及其現代教益》,《東啍論叢》1995 年第 1 期。 